\title{
Information in Medicine
}

\section{Are you making the most of "Index Medicus"?}

\author{
JACQUELINE WELCH
}

When you need to unearth articles on your topic of interest, do you visit your nearest hospital/medical library? If so, do you head for the librarian and ask for a search to be done or do you make for the shelves holding Index Medicus? If the former you will probably observe that the librarian goes to Index Medicus to carry out your search for you and you will be lucky if your search is done as soon as you would like. And, with all due respect to library staff, they do not know your subject as well as you do, even though their searching technique may be better. So why not brush up your own abilities vis-à-vis creating a search profile and be sure you have located all possible relevant citations?

Many indexing and abstracting journals exist, and only the largest and most opulent libraries hold them all. Most medical libraries, however, hold Index Medicus, which is the most prestigious of indexing tools, as well as being the best known in terms of rapid subject retrieval. Although not comprehensive in coverage, Index Medicus indexes over 5000 of the world's principal medical and biomedical journals. The listing of those journals covered is given, both in their full and abbreviated form. This list is updated annually to take account of important new publications and to report changes in titles. Other indexing and abstracting tools on specific subjects exist-for instance, on hygiene, tropical medicine, psychology, and endocrinology, to name but a few. Any of these would be fuller in its coverage of its particular specialty than is Index Medicus, but the beauty of the latter is that it does cover nearly all medical and paramedical publications and is a more than adequate holding for a general medical library.

The 12 monthly issues of Index Medicus become irksome to handle towards the end of the year, but by the following spring the set of cumulated volumes has arrived, and the chore of ploughing through a dozen single parts is over for another year.

\section{Time scale}

Before going into details a word of caution about the time-scale of Index Medicus. (All indexing and abstracting journals have this in common to a greater or lesser degree.) When searching in Index Medicus for 1981 you should not be surprised to find many citations from 1980 journals. The article, after all, had to be read, analysed, and indexed, possibly translated too, before being cited. Since Index Medicus is produced by the National Library of Medicine in Washington, most American articles are about three months late in being quoted. Most British articles appear six or more months later, while many European publications, especially if they have had to be translated, are nine months to a year late. Remember this and you will be able to gauge which year's index to scan. Spelling is American too: don't imagine the term oesophagus does not exist. It will be found under esophagus.

\section{Medical subject headings (MeSH)}

The first thing to do when starting a search is to consult the medical subject headings ( $\mathrm{MeSH}$ ) for the year in question: $\mathrm{MeSH}$ is issued every January and contains newly introduced terms as well as terms deleted, so it is essential to consult the relevant $\mathrm{MeSH}$. See if the term you seek is listed-for instance, umbilical hernia. You will find that umbilical hernia is printed in small type and refers you to hernia, umbilical. This is a straightforward cross-reference: when hernia, umbilical is looked up it refers you back to umbilical hernia using the symbol $X$ (for see). Another type of cross-reference is see under $(X U)$. Hock, for example, tells you to see under hindlimb: hindlimb too has a cross-reference, namely $X U$ hock. See related $(X R)$ is the third type of cross-reference, and is used as a form of prompt. For example, were you to look up the term labor, induced you would be advised to see related oxytocics. Oxytocics in turn has the cross-reference $X R$ labor, induced. You can be confident of finding the term you need, even though not precisely as you phrased it, or possibly supplementary terms, by means of these cross-references. In general the qualifying adjective follows the noun-for instance, sarcoma, osteogenic; bile ducts, intrahepatic; neoplasms, multiple primary. So go initially for the substantive.

A code or codes accompanies each $\mathrm{MeSH}$ term. For the importance of these consult the second part of $\mathrm{MeSH}$, the list of categories and subheadings, that prefaces a hierarchical tree structure of the main headings. Category A is anatomy: it has 16 subcategories consisting of such elements as musculoskeletal system, tissue types, cells, embryonic structures. A term such as ileal diseases (C6.405.469.420+) comes into category C diseases, subcategory 6 digestive system diseases. Looking at C6.405.469. $420+$ in the tree structures the importance of the plus sign becomes apparent. Two terms are subsumed under ileal diseases-ileal neoplasms and ileitis. So if, using hard-copy Index Medicus, you were searching for ileal neoplasms or ileitis you would be unsuccessful if you were to consult the citations under ileal diseases. If you used Medline ${ }^{1}$ (the online application of Index Medicus) you could "explode" ileal diseases if you wished, and all three terms would be searched. A term may have more than one code. Plastics, for example, has two codes: D25.720. $716+$ chemical and drugs (biomedical and dental materials) and $\mathrm{J} 1.637 .695 .611+$ technology, industry, agriculture, food. In this case if you were searching online you could select whichever aspect of Plastics was more immediately relevant by citing the pertinent code rather than the word "plastics."

\section{Subheadings}

Citations under each main heading are grouped into blocks of 
references arranged under subheadings. As with main headings every subheading is followed by one or more main category codes $(A-N, Z)$. These indicate that the subheading in question may be applied to main headings in these categories. In any case the limitations are self-evident. The subheading "blood" (used for the presence of substances in the blood or for changes in the blood in pathological conditions) can be applied to vertebrates, to diseases, to chemicals and drugs, and to mental disorders. Plainly, it could never be run with anatomical terms or therapeutic techniques or biological or physical sciences. The value of the correct application of subheadings is that it can reduce your search radically and bring you to the very nub of your search. If you are looking for the causes of carotid artery thrombosis, a fairly large section on its own, you need concern yourself only with the citations under the subheading "etiology." The same economy of effort would hold good for diagnosis, drug therapy, therapy, metabolism, mortality, etc.

\section{Language}

English language articles are always listed before those in foreign languages. The former are cited in alphabetical order of the journal in which they appear. Foreign language articles are quoted in brackets and are listed in alphabetical order of language (which is indicated) and within that in order of journal title. Any abstract in English is mentioned.

\section{Review articles}

Each monthly issue, as well as the cumulated volumes, carries a separate section of review articles. This is an ideal way of obtaining an adequate number of references without searching over several years. Sadly yet another special section, multiauthor monographs, has this year (1982) been discontinued.

Both the cumulative volumes and the single issues contain an author index for that year/month, ideal for checking on articles by known authors.

Nothing more than adequate subject knowledge, which you have and which the library staff may not have, and the basic rules here outlined are necessary for a comprehensive and successful search. But practice helps too. If you want to cover literally everything on a given topic you probably need a definitive standard text book on the subject and not random journal references. But if you still feel the need to plumb journal publications, you might just persuade the librarian to allow you to photocopy the whole section you need out of Index Medicus over the years you want to cover.

\section{Reference}

1 Welch J. Computerised information retrieval services in a teaching hospital. $\mathrm{Br}$ Med $\mathcal{F}$ 1980;280:1433-4.

(Accepted 26 fuly 1982)

\section{MATERIA NON MEDICA}

\section{The lesser black-backed gull in suburbia}

Thirty-five years ago the lesser black-backed gull was rather uncommon on the shore of Glamorgan, and it was interesting to identify the occasional individual among a flock of herring gulls. In the interim numbers of the species have increased considerably, and now very many roost and nest on the islands of Steep Holm and Flat Holm. One reason adduced for their proliferation is the easy availability of food, for they feed on the large refuse tips which have appeared near the coast.

Members of this species first visited my garden to feed on offal and other remnants about 10 years ago. Many of my interested colleagues who lived in large urban conurbations were sceptical when I reported this, and suggested that I was mistaken, but now the birds squat indiscriminately on rooftops around us, keeping keen eyes open for edibles in the gardens, swooping down in groups of four or five to fight on our lawns for the food offered.

In Penarth household refuse is now placed in plastic bags which are tied at the mouth and then placed unprotected on the verge to await collection. Dogs and cats, having a highly developed sense of smell, often tear the bags open and leave litter strewn over the pavements, to the intense irritation and embarrassment of the populace. Recently I observed a lesser black-backed gull alight in the road, advance towards an intact refuse bag and tear it open with one fierce peck from its powerful beak. Within seconds it was extracting and swallowing edible refuse at a furious rate, and when faced with a largish bone flew with the prize to a nearby flat roof. This extraordinary accomplishment surely cannot be derived from the bird's sense of smell, for I believe this is poorly developed. The action must be imitative, the bird having observed the predations of animals and benefited therefrom. Such initiative excites admiration and perhaps explains the proliferation of the species.

Our residential area is ruled by a "supremo" who has reigned over six or seven birds for three years. Remarkably, he has what might be considered a serious disability; his right leg is grossly deformed and ankylosed at the ankle, forcing him to stand on the "good" leg and merely "tip" the deformed one at intervals. Despite this he rules his territory with fierce aggression and is a living contradiction of "survival of the fittest." Perhaps he owes his existence to having become domesticated to a slight degree.
Several birds have indulged in courtship on our flat roof, and I await the first nesting with interest. It would be the culmination of a notable advance of the species in the past three decades.-E H HORTON, retired physician, Penarth, South Glamorgan.

\section{Treecreepers}

Hearing tapping noises coming from behind some old timber, I expected to find a nuthatch opening a hazel nut but, instead, I discovered a treecreeper which was probing vigorously for bark insects. Certainly treecreepers are birds which are specialised for living in mature woodland and they even sleep in ovoid, upright hollows which they excavate themselves in soft bark. Their precision tool is the thin, pointed decurved bill, with which the bird can seize and then extract invertebrate food lying deep in bark cracks and furrows; moreover, when carrying this out, the creeper is usually seen to be ascending a tree trunk.

Such climbing on vertical surfaces is achieved because of its sharply pointed claws which tip the long toes; the bird does not normally progress down trees as do nuthatches, but it does move on the undersides of large branches and, at times, it will encircle one or, occasionally, just walk backwards. Another important structure for the treecreeper is its tough, stiff forked tail. This tail, when pressed against a trunk, gives support to the clinging bird so that it can pick food items from awkwardly shaped bark recesses.

Looking like a brown butterfly when in flight, a treecreeper becomes quite inconspicuous after alighting on a tree trunk. The streaked and brown patterning of its back, neck, and head ensures admirable protective colouring; the underparts, however, are satin white and will show the position of the bird should it twist itself to investigate a cavity. When watching a pair feeding young in a crack in an old tree, I noted that the birds always approached the hole by clambering obliquely towards it. Similarly, the creepers climbed upwards after emerging; thus, there was less chance of revealing the white belly and hence the position of the nest. The same type of behaviour had been observed during nest building, but then the bird had to rotate itself in order to introduce long twigs: under such circumstances the nest site could have been noted by an aiert predator.

Crane-flies, larvae, and spiders were carried to the nest. When the fledglings emerge they cling on to bark, the material on which they will rely, as adults, to provide their security, shelter, and food.-PHILIP RADFORD, Somerset. 